JKEP

Vol 5, No 1, Mei 2020

ISSN: 2354-6042 (Print)

ISSN : 2354-6050 (Online)

\title{
Dilema Etik Dalam Assisted Reproductive Technology
}

(ART)

Nurma Zela Gustina, La Ode Abd Rahman

Fakultas Ilmu Keperawatan Universitas Indonesia

Email : nurmazelagustina@gmail.com

\section{Artikel history}

Dikirim, Dec $12^{\text {th }}, 2019$

Ditinjau, April $24^{\text {th }}, 2020$

Diterima, Mei $2^{\text {st }}, 2020$

\begin{abstract}
The development of ART in the community that is important to do is related to ethics and dilemmas that may arise in the use of ART. The Improvement of ART user as solution in Infertility but also not able on rule of ART. This study to provide an overview as well as an overview of the results of a literature review related to ethical dilemmas in actions assisted by reproductive technology. In this study using the literature review method. In ART actions related to problems that become related to embryonic donations that allow recipients of embryonic donors to get disease transmission to later generations. The application of ethics by nurses in ART is able to consider badly the event by exposing embryonic donors and recipients to establish communication in the future. The importance of applying ethics as a better way of preventing diseases arising after ART actions both for donors and donor recipients.
\end{abstract}

Keywords: assisted reproductive technology (ART), embryonic donors, ethics

\begin{abstract}
Abstrak
Perkembangan ART dalam komunitas masyarakat yang meningkat pesat penting untuk dilakukan pengawasan terkait etik dan dilema yang mungkin timbul dalam penggunaan ART. Meningkatnya minat terhadap penggunaan ART sebagai solusi Infertilitas di masyarakat belum disertai dengan peraturan terkait etik dalam penggunaan ART. Tujuan penelitian adalah memberikan gagasan serta gambaran dari hasil literatur review terkait dilemma etik dalam tindakan assisted reproduvtive technology. Dalam studi ini menggunakan metode literatur review. Dalam tindakan ART terdapat masalah etik yang menjadi perdebatan terkait donasi embrio yang memungkinkan para penerima donor embrio mendapatkan transmisi penyakit kepada generasi selanjutnya. Penerapan etik oleh perawat dalam tindakan ART ini mampu mempertimbangkan kemungkinan buruk terhadap kejadian tersebut dengan mengungkap pendonor dan penerima embrio untuk menjalin komunikasi di masa depan. Pentingnya penerapan etik sebagai suatu cara mencegah kemungkinan buruk seperti penyakit yang timbul pasca tindakan ART baik terhadap pendonor maupun penerima donor
\end{abstract}

Kata kunci: assisted reproductive technology (ART), donor embrio, etik 


\section{PENDAHULUAN}

Infertilitas adalah suatu penyakit yang menimbulkan kecacatan dan sebagai sebuah gangguan fungsi (WHO dalam (Vander Borght \& Wyns, 2018). Infertilitas pada wanita yang dikarakteristikan oleh kegagalan dalam membentuk kehamilan secara klinis setelah 12 bulan dalam keadaan normal, hubungan seksual yang tidak aman atau penurunan kemampuan seseorang untuk bereproduksi, baik individual atau pasangan. Hubungan seksual yang teratur adalah suatu yang penting dalam menentukan sebuah kehamilan (Yatsenko\&Rajkovic,2019). Sebagai solusi dalam infertilitas dilakukan berbagai pengobatan seperti dikelompokan dalam assited reproductive technology (ART) yakni intracytoplasmic sperm injection (ICSI), in-vitro fertilisation (IVF) (Bernard M Y Cheung, 2019).

Sejak tindakan yang pertama kali sukses dilakukan dengan metode konvensional fertilisasi in vitro (IVF) pada tahun 1978, assisted reproductive technology (ART) telah menjadi bagian integral dari kesehatan dan sekarang telah menjadi kunci dalam perencanaan keluarga. Paling sedikit ada 5 juta bayi yang lahir dari hasil ART dan di beberapa negara proporsi kelahiran bayi setelah adanya ART sekarang melebihi 5\%. Sebagai dampak dari ART terhadap komunitas, masyarakat dan demograpi diharapkan adanya pengawasan yang adekuat terkait kemungkinan adanya peristiwa buruk terhadap teknologi baru yang diperkenalkan (De Geyter, 2019). Untuk itu pengetahuan perawat terkait etik dan dilema yang timbul dalam penggunaan ART di lingkup social dan budaya didalam komunitas masih sangat perlu di perhatikan lebih lanjut.

\section{METODE}

Metode yang digunakan dalam penelitian ini adalah literature review, yaitu dimana sebuah studi yang menganalisis beberapa literatur yang terpilih dari berbagai sumber yang dibuat menjadi sebuah gagasan atau kesimpulan dari sebuah ide yang baru. Jurnal yang digunakan dalam studi ini adalah jurnal-jurnal yang membahas mengenai topik dengan 2 (dua) kategori kata kunci yaitu; 1) Nursing 
Informatics on Assited Reproductive

Technology; dan 2) Nursing Ethics

Dilema on Assited Reproductive

Technology. Penelusuran jurnal dalam

studi ini melalui Online Database

diantaranya: ScienceDirect, Clinical

Key, dan ProQuest dari tahun 2016-

2019.

\section{KAJIAN LITERATUR}

Dewasa ini penggunaan assisted reproductive technology (ART) sebagai solusi infertilitas telah banyak dilakukan, contohnya seperti donasi embrio, yang digunakan untuk ketiadaan sperma atau telur yang memungkinkan untuk transmisi penyakit genetic pada generasi selanjutnya. Sejak pertama kali pengobatan dengan menggunakan ART ditahun 1978 berhasil dilakukan, ART telah menjadi bagian integral dari pengobatan modern dan saat ini berperan penting dalam keluarga berencana (De Geyter, 2019). Donasi embrio menjadi salah satu teknologi dalam ART berdasarkan literatur yang ditemukan donasi embrio menjadi kontroversial dikarenakan metode ini membawa individu baru dari luar lingkaran keluarga dimana kehadirannya dapat menyebabkan banyak masalah etika serta mempersulit perancangan proses donasi embrio. Penting untuk diketahui terkait sudut pandang antara pendonor embrio dan penerima embrio agar dapat mengungkap tantangan etis yang ada dalam donasi embrio pada ART juga mengedepankan prinsip keadial serta menghormati otonomi masing-masing baik penerima dan pendonor embrio pada pusat layanan kesehatan yang menyediakan layanan ART dengan teknologi donasi embrio tersebut dengan tetap mengedepankan prinsip etik (Taebi, Bahrami, BagheriLankarani, \& Shahriari, 2018).

Kontroversi yang terjadi dalam teknologi ART seperti donasi embrio yang pendonornya dirahasiakan atau dtaa pendonor yang belum lengkap serta hasil yang ada dari program ART yang dilakukan pada masyarakat yang belum maksimal pendataannya harus menjadi perhatian bagi pemerintah, karena pada setiap tahunnya minat menggunakan ART dalam upaya reproduksi pada masyarakat semakin meningkat namun tidak disertai dengan pendataan yang kumulatif (De Geyter, 2019). Diketahui dalam ART ini 70,20\% aspek justice yang ada, lalu aspek aunotomy sebesar 
42,57\% namun prinsip etik lain, belum terkaji secara maksimal

(Taebi et al., 2018). Pentingnya bagi tenaga kesehatan dalam hal

ini pelaku utama dalam kegiatan ART untuk dapat mengutamakan prinsip etik dalam setiap tindakan ART.

Berikut merupakan jurnal-jurnal pilihan yang peneliti analisis dalam studi literature review ini:

Tabel 1. Rincian hasil jurnal pilihan utama untuk literature review

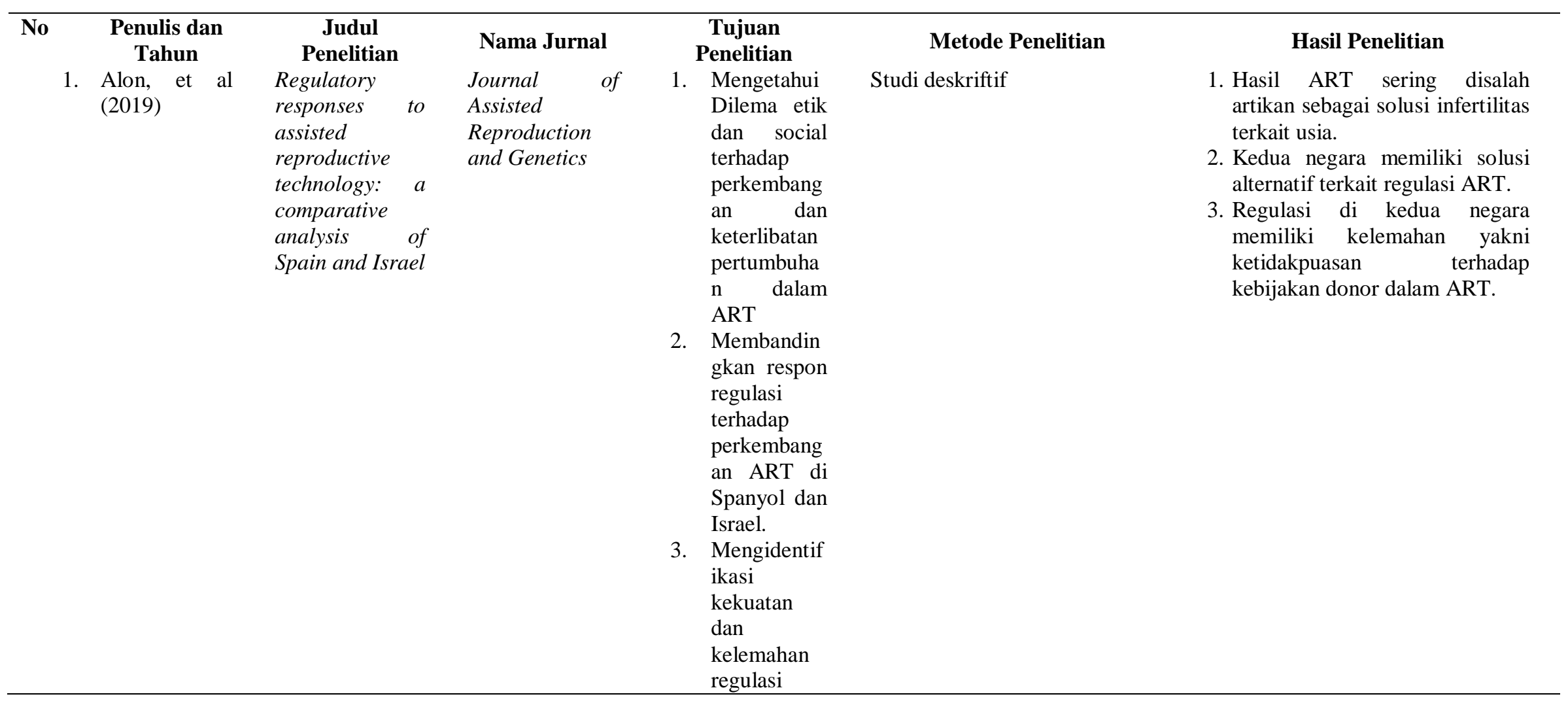




\begin{tabular}{|c|c|c|c|c|c|c|}
\hline No & $\begin{array}{l}\text { Penulis dan } \\
\text { Tahun }\end{array}$ & $\begin{array}{c}\text { Judul } \\
\text { Penelitian }\end{array}$ & Nama Jurnal & $\begin{array}{l}\text { Tujuan } \\
\text { Penelitian } \\
\text { terkait ART } \\
\text { di Spanyol } \\
\text { dan Israel. }\end{array}$ & Metode Penelitian & Hasil Penelitian \\
\hline 2. & $\begin{array}{l}\text { Bernard M Y } \\
\text { Cheung, K. S. } \\
\text { L. L. (2019) }\end{array}$ & $\begin{array}{l}\text { Evidence-based } \\
\text { medicine and } \\
\text { infertility } \\
\text { treatment }\end{array}$ & $\begin{array}{l}\text { Center for } \\
\text { Reproductive } \\
\text { Medicine, } \\
\text { Amsterdam } \\
\text { Reproduction \& } \\
\text { Development } \\
\text { Institute }\end{array}$ & $\begin{array}{l}\text { Untuk } \\
\text { mengetahui } \\
\text { manfaat dari ART } \\
\text { pada pasangan } \\
\text { yang infertilitas, } \\
\text { serta dampak } \\
\text { komersil terhadap } \\
\text { ART. }\end{array}$ & Literatur review & $\begin{array}{l}\text { Di negara dengan asurans } \\
\text { kesehatan nasional yang menjamin } \\
\text { perawatan fertilita seharusnya } \\
\text { mampu menahan diri dari manfaa } \\
\text { yang tidak diketahui kecual } \\
\text { pengobatan tersebut ditawaran } \\
\text { dalam konteks uji klinis yang } \\
\text { dirancang dengan baik. }\end{array}$ \\
\hline 3. & $\begin{array}{l}\text { De Geyter, C. } \\
(2019)\end{array}$ & $\begin{array}{l}\text { Assisted } \\
\text { reproductive } \\
\text { technology: } \\
\text { Impact on } \\
\text { society and } \\
\text { need for } \\
\text { surveillance }\end{array}$ & $\begin{array}{l}\text { Best Practice \& } \\
\text { Research } \\
\text { Clinical } \\
\text { Endocrinology } \\
\& \text { Metabolism }\end{array}$ & $\begin{array}{l}\text { Untuk } \\
\text { mengetahui } \\
\text { dampak dari ART } \\
\text { pada masyarakat } \\
\text { dan demografi. }\end{array}$ & Studi cross-sectional. & $\begin{array}{l}\text { Dampak dari ART seharusnya } \\
\text { mampu membuat sebuah } \\
\text { pelacakan dan pengawasan } \\
\text { terhadap stimulasi ofovarian atau } \\
\text { kumpulan oocytes. Terhadap } \\
\text { seluruh stakeholder, mamp } \\
\text { mengontrol kualitas dan penuh } \\
\text { transparansi. }\end{array}$ \\
\hline 4. & $\begin{array}{l}\text { Dunietz, et al } \\
\text { (2017) }\end{array}$ & $\begin{array}{l}\text { Assisted } \\
\text { reproductive } \\
\text { and risk of } \\
\text { preterm birth in } \\
\text { singletons by } \\
\text { infertility }\end{array}$ & $\begin{array}{l}\text { Journal of } \\
\text { Assisted } \\
\text { Reproduction } \\
\text { and Genetics }\end{array}$ & $\begin{array}{lr}\text { Untuk } & \text { menguji } \\
\text { spektrum } & \text { terkait } \\
\text { diagnose } & \\
\text { infertilitas } & \text { dan } \\
\text { tindakan } & \text { ART } \\
\text { yang } & \end{array}$ & Studi korelasional & $\begin{array}{l}\text { Hubungan ART terhadap } \\
\text { peningkatan resiko PTB terhadap } \\
\text { semua diagnose infertilitas } \\
\text { diketahui bahwa tidak didapatkan } \\
\text { hubungan antara resiko PTB } \\
\text { terhadap ART. }\end{array}$ \\
\hline
\end{tabular}




\begin{tabular}{|c|c|c|c|c|c|c|}
\hline No & $\begin{array}{c}\text { Penulis dan } \\
\text { Tahun }\end{array}$ & \begin{tabular}{l}
\multicolumn{2}{c}{ Judul } \\
\multicolumn{2}{c}{ Penelitian } \\
diagnoses and \\
treatment \\
modalities: a \\
population- \\
based study.
\end{tabular} & Nama Jurnal & \begin{tabular}{l}
\multicolumn{2}{c}{ Tujuan } \\
Penelitian \\
dihubungkan \\
dengan resiko \\
pretem $\quad$ birth \\
(PTB)..
\end{tabular} & Metode Penelitian & Hasil Penelitian \\
\hline 5 . & $\begin{array}{l}\text { Ethics } \\
\text { Committee of } \\
\text { the American } \\
\text { Society for } \\
\text { Reproductive } \\
\text { Medicine. } \\
\text { Electronic } \\
\text { address, A. a. } \\
\text { o., \& Ethics } \\
\text { Committee of } \\
\text { the American } \\
\text { Society for } \\
\text { Reproductive, } \\
\text { M. (2016) } \\
\text { Messerlian, } \\
\text { C., Platt, R. } \\
\text { W., Tan, S. } \\
\text { L., Gagnon, } \\
\text { R., \& Basso, } \\
\text { O. (2015) }\end{array}$ & $\begin{array}{l}\text { Oocyte or } \\
\text { embryo } \\
\text { donation to } \\
\text { women of } \\
\text { advanced } \\
\text { reproductive } \\
\text { age: an Ethics } \\
\text { Committee } \\
\text { opinion. }\end{array}$ & $\begin{array}{l}\text { Ethics } \\
\text { Committee of } \\
\text { the American } \\
\text { Society for } \\
\text { Reproductive } \\
\text { Medicine }\end{array}$ & 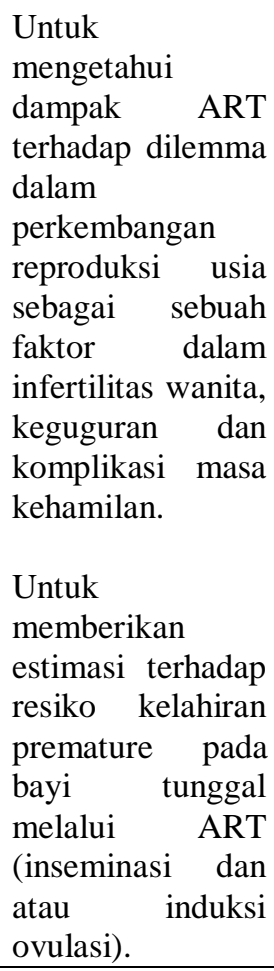 & Literatur review & $\begin{array}{l}\text { Diketahui bahwa terkait dilemma } \\
\text { terhadap ART dan dikaitkan } \\
\text { dengan sifat kehamlian yang } \\
\text { beresiko tinggi tidak dianjurkan } \\
\text { untuk melakukan pengobatan } \\
\text { umum. }\end{array}$ \\
\hline
\end{tabular}




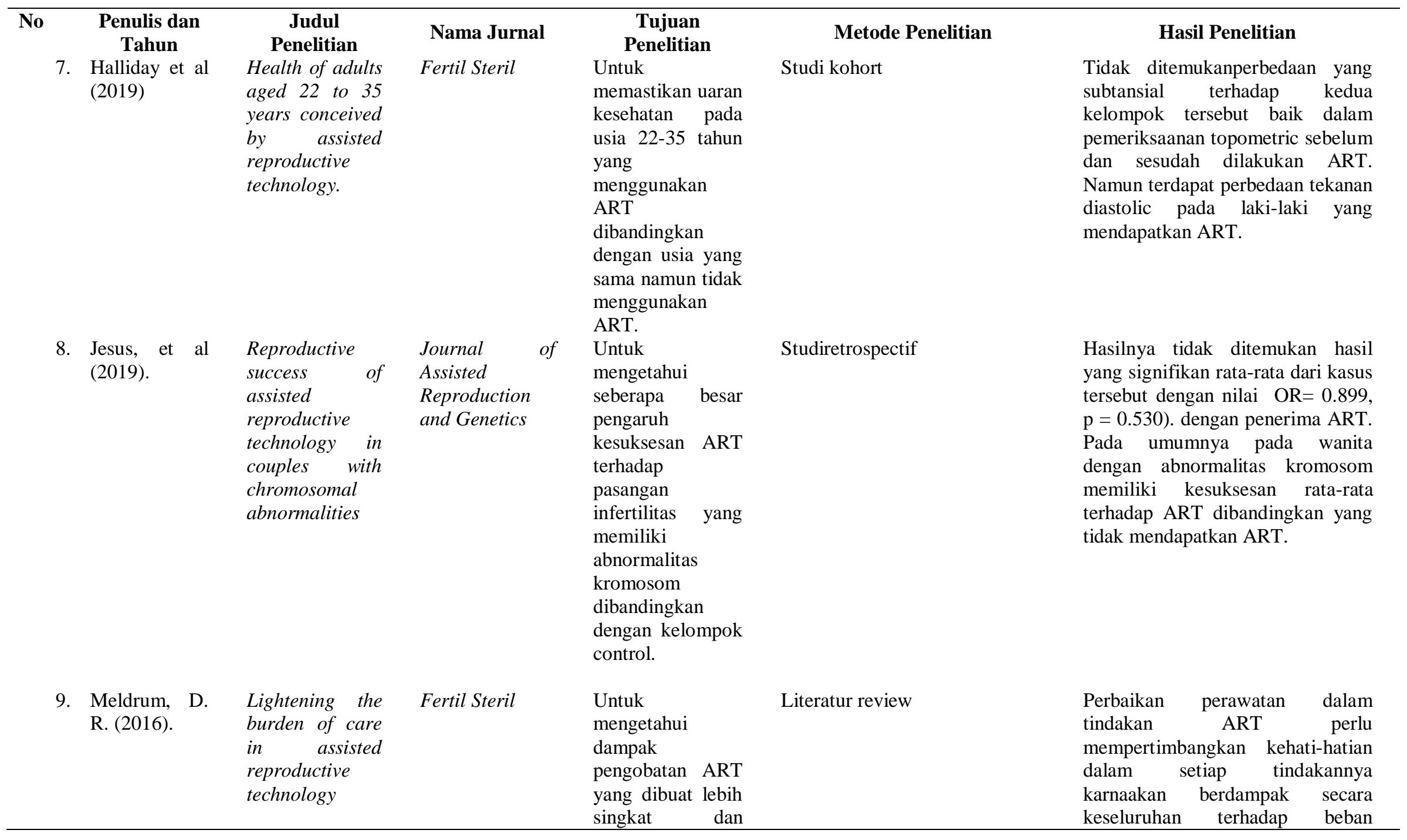




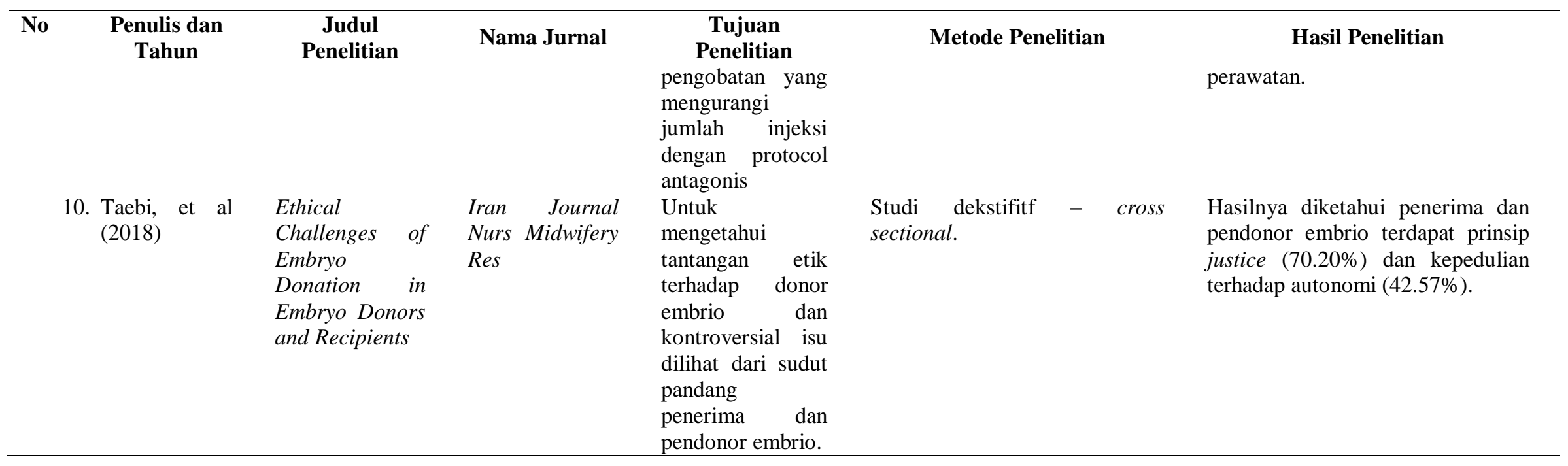




\section{KESIMPULAN DAN REKOMENDASI}

Prinsip etik harus selalu diperhatikan bagi setiap tenaga kesehatan khususnya perawat, dalam kondisi tindakan ART, setiap penerima donor maupun pandoro embrio harus dilakukan pendataan yang komprehensif. Keempat aspek etik autonomy, beneficence, nonmaleficence, dan justice harus diperhatikan dalam pinsip pemberian donor embrio dan penerima donor embrio, hambatan yang ada dalam pelayanan bukan menjadi alasan bagi tenaga kesehatan untuk mengesampingkan prinsip etik dalam setiap tindakan ART (Taebi et al., 2018).

Sebagai rekomendasi penulis kepada tenaga kesehatan khususnya perawat komunitas adalah untuk terus mengembangkan keilmuan dan menerapkan etik sebaik mungkin dalam masyarakat. Masih ditemukannya kasus infertilitas didalam masyarakat dan penggunaan ART sebagai solusi terkait infertilitas tersebut menjadi tantangan etik tersendiri terkait tindakan dalam ART, maka perlunya peran perawat sebagai advocacy membantu klien untuk memilih tindakan yang dapat dilakukan serta menjunjung tinggi prinsip etik dalam profesi sebagai penuntunkeilmuan.

Implikasi terkait assisted reproductive technology (ART) adalah suatu teknologi yang membantu wanita dan pria atau pasangan yang mengalami infertilitas untuk dapat melakukan pembuahan dalam memaksimalkan tingkat kehamilan yang didalamnya terdapat prinsip etik yang perlu diterapkan olehtenaga kesehatan. Sebagai seorang perawat komunitas penting untuk membantu klien mengetahui gangguan fertilitas yang dialami lalu kemudian membantu klien untuk mendapatkan pengobatan terbaik dan mempertimbangkan prinsip etik dalam setiaptindakannya.

\section{UCAPAN TERIMA KASIH}

Penulis mengucapkan terima kasih kepada berbagai pihak yang telah memberikan bantuan selama penulisan literatur review ini. Ucapan terima kasih ini diberikan kepada Fakultas Ilmu Keperawatan Universitas Indonesia program Keperawatan Komunitas. 


\section{DAFTAR PUSTAKA}

Alon, I., Guimon, J., \& UrbanosGarrido, R. (2019). Regulatory responses to assisted reproductive technology: a comparative analysis of Spain and Israel. $J$ Assist Reprod Genet, 36(8), 1665-1681. doi:10.1007/s10815-019-015257

Bernard M Y Cheung, K. S. L. L. (2019). Evidence-based medicine and infertility treatment. Vol 393. doi:10.1016/S01406736(19)30200-4

De Geyter, C. (2019). Assisted reproductive technology: Impact on society and need for surveillance. Best Pract Res Clin Endocrinol Metab, 33(1), 3-8. doi:10.1016/j.beem.2019.01.004

Dunietz, G. L., Holzman, C., Zhang, Y., Li, C., Todem, D., Boulet, S. L.,Diamond, M. P. (2017). Assisted reproductive and risk of preterm birth in singletons by infertility diagnoses and treatment modalities: a population-based study. J Assist Reprod Genet, 34(11), $1529-$ 1535.doi:10.1007/s10815-0171003-6
Ethics Committee of the American Society for Reproductive Medicine. Electronic address, A. a. o., \& Ethics Committee of the American Society for Reproductive, M. (2016). Oocyte or embryo donation to women of advanced reproductive age: an Ethics Committee opinion. Fertil Steril, 106(5), e3-e7. doi:10.1016/j.fertnstert.2016.07. 002

Ghuman,N.,\& Ramalingam, M. (2018).Male infertility. Obstetrics, Gynaecology \& Reproductive Medicine, 28(1), 7-14.doi:10.1016 /j.ogrm.2017.10.007

Halliday, J., Lewis, S., Kennedy, J., Burgner, D. P., Juonala, M., Hammarberg, K., . . . McLachlan, R. (2019). Health of adults aged 22 to 35 years conceived by assisted reproductive technology. Fertil Steril, 112(1), 130-139. doi:10.1016/j.fertnstert.2019.03. 001

Jesus, A. R., Silva-Soares, S., Silva, J., Severo, M., Barros, A., \& Doria, S. (2019). Reproductive success of assisted reproductive technology in couples with chromosomal abnormalities. $J$ Assist Reprod Genet, 36(7), 1471-1479. doi:10.1007/s10815019-01486-x 
Meldrum, D. R. (2016). "Lightening the burden of care in assisted reproductive technology." Fertil Steril 105(5): 1144-1145

Messerlian, C., Platt, R. W., Tan, S. L., Gagnon, R., \& Basso, O. (2015). Low-technology assisted reproduction and the risk of preterm birth in a hospital-based cohort. Fertil Steril, 103(1), 8188 e82. doi:10.1016/j.fertnstert.2014.10. 006

Taebi, M., Bahrami, R., BagheriLankarani, N., \& Shahriari, M. (2018). Ethical Challenges of Embryo Donation in Embryo Donors and Recipients. Iran $J$ Nurs Midwifery Res, 23(1), 3639.

doi:10.4103/ijnmr.IJNMR_162_ 16
Vander Borght, M., \& Wyns, C. (2018). Fertility and infertility: Definition and epidemiology. Clin Biochem, 62, -10.doi:10.1016/j.clinbiochem. 2018.03.012

Yatsenko, S. A., \& Rajkovic, A. (2019). Genetics of human female infertility. Biol Reprod. doi:10.1093/biolre/i 